Proceeding Paper

\title{
A Preliminary Study of Winter Atmospheric River's Precipitation Characteristics Using Satellite Data over Galicia (NW Spain) ${ }^{\dagger}$
}

\author{
Elham Ghasemifar 1,* , Jorge Eiras-Barca ${ }^{2,3}$, Iago Algarra ${ }^{2}$, Alexandre M. Ramos ${ }^{4}$, Manuchehr Farajzadeh ${ }^{\text {, }}$ \\ Raquel Nieto ${ }^{2}$ and Luis Gimeno ${ }^{2}$
}

Citation: Ghasemifar, E.; Eiras-Barca, J.; Algarra, I.; Ramos, A.M.;

Farajzadeh, M.; Nieto, R.; Gimeno, L. A Preliminary Study of Winter Atmospheric River's Precipitation Characteristics Using Satellite Data over Galicia (NW Spain). Environ. Sci. Proc. 2021, 4, 26. https://doi.org/ 10.3390/ecas2020-08119

Academic Editor: Anthony R. Lupo

Published: 13 November 2020

Publisher's Note: MDPI stays neutral with regard to jurisdictional claims in published maps and institutional affiliations.

Copyright: (C) 2020 by the authors. Licensee MDPI, Basel, Switzerland. This article is an open access article distributed under the terms and conditions of the Creative Commons Attribution (CC BY) license (http://creativecommons.org/licenses/by/4.0/).
1 Department of Physical Geography, Tarbiat Modares University, Tehran 14155-4838, Iran; farajzam@modares.ac.ir

2 Environmental Physics Laboratory (EPhysLab), CIM-UVIGO, Universidade de Vigo, 32004 Ourense, Spain; jeiras@uvigo.es (J.E.-B.); ialgarra@uvigo.es (I.A.); rnieto@uvigo.es (R.N.); 1.gimeno@uvigo.es (L.G.)

3 Department of Atmospheric Sciences, University of Illinois at Urbana, Champaign, IL 61801, USA

4 Instituto Dom Luiz, Faculdade de Ciências, Universidade de Lisboa, 1749-016 Lisbon, Portugal; amramos@fc.ul.pt

* Correspondence: elham.ghasemifar@modares.ac.ir

† Presented at the 3rd International Electronic Conference on Atmospheric Sciences, 16-30 November 2020; Available online: https://ecas2020.sciforum.net/.

\begin{abstract}
This brief research report is aimed to make a first approach to the study of the type of precipitation associated with a set of atmospheric river (AR) events over the Atlantic region of Galicia. Fifteen ARs that made landfall in the Spanish region of Galicia have been analyzed using the 2B-GEOPROF and 2C-PRECIP-COLUMN from the CloudSat cloud profiling radar (CPR). An estimation of the relative ratio between warm and cold precipitation associated with each event is provided. Broadly speaking, cold precipitation accounts for $80 \%$ of the total. This value is slightly higher than the already stated for Pacific AR events. However, similar mean rain rates $(0.35 \mathrm{~mm} / \mathrm{h}$ for the warm precipitation and $1.16 \mathrm{~mm} / \mathrm{h}$ for the cold counterpart) to those reported by the literature have been obtained. In the absence of a more comprehensive and conclusive statistic, it seems that cold precipitation is predominant along the central axis of a well-developed AR. In this central core of the AR, the bulk of the moisture remains in the lower levels, and the freezing level (FL) is low. According to these results, the interaction between the warm conveyor and the cold conveyor belt may eventually raise the FL to upper levels, leading the warm fraction to play a more important-even though still secondary-role.
\end{abstract}

Keywords: CloudSat; warm precipitation; atmospheric rivers; Galicia; Spain

\section{Introduction}

Atmospheric rivers (ARs) are one of the well-recognized precursors of extreme precipitation in extensive areas around the globe (e.g., [1], and references therein). The importance of ARs as precursors of extreme precipitation has been stated not only for the US West Coast (e.g., [2-4]) or the European West Coast (e.g., [5]), but also for diverse regions of varied climatic conditions such as Greenland [6], the North-Western Pacific [7], the Antarctica [8], or South Africa [9], among others. ARs are not more than coherent structures carrying unusual amounts of moisture, mostly in the warm sector of extratropical cyclones and mostly from (sub)tropical to middle latitudes [10]. When such a vast amount of moisture contained within the AR is forced to ascend, either due to thermodynamical forcings, a dynamical mechanism, and or due to the interaction with the orography, robust condensation processes are enhanced and may trigger anomalous precipitation. 
On the one hand, in the region of interest for this work (Galicia, NW Spain, Figure 1), enough literature demonstrated the critical role played by ARs in the local hydroclimatology. Even though most ARs do not lead to extreme precipitation, most of the extreme precipitation events are preceded by, or coincide with, an AR detection [11-14]. This is especially true in the winter months, when the number of Atlantic baroclinic structures landfalling on the shore is high. On the other hand, satellite radar data and passive imagery have been widely used to analyze AR characteristics over the Northeastern Pacific (e.g., [15-17]). Nevertheless, there is still a lack of this analysis over the Eastern Atlantic region and, particularly, over the area of interest in this article. Satellite radar data may provide the vertical characteristics of the water contained in the column, and therefore allow for an independent analysis of the warm and cold precipitation rates. Warm precipitation is associated with low-level cloudiness and warmer types of clouds. This kind of cloudiness is accepted to play a relevant role in the hydrological cycle and energy budget (e.g., [18]).

In this connection, Matrosov [19] provided a good estimation for Pacific ARs. Analyzing more than 200 case studies, they found that $30 \%$ of the ARs could be defined as "warm events". However, to the best of our knowledge, no previous research has analyzed the characteristics of the extreme rainfall under our region of interest to the date.

\section{Data and Methods}

The AR detections have been retrieved from the AR database (ERA-Interim version) published along with Guan and Waliser [20]. This work analyzes all the AR events that occur in coincidence with the overpass of the CloudSat satellite [21,22] and that led to anomalous precipitation events over the Atlantic region of Galicia, as defined in Lorenzo et al. [23]. 2B-GEOPROF and 2C-PRECIP-COLUMN from the CloudSat cloud profiling radar (CPR), with 125 bins and more than 37,000 profiles, have been used to estimate the freezing level (FL) and classify the precipitation associated with the AR event in terms of the warm and cold fraction; following the procedure stated in Matrosov [24].

According to the methodology stated in Matrosov [24], values of reflectivity in $\mathrm{dB}$ above 25 are not considered in the analysis in order to filter the ground clutter. Values below 0 are also removed in order to filter drizzle. It should be noted that radar reflectivity equal than 0 is assumed with rain rate equal $1 \mathrm{~mm}$ according to Field and Heymsfield, [25]. In other words, the dBZe greater than 0 is certainly rainy $[18,26]$. The radar echo corresponding to the certainly rainy profiles of the vertical levels (also called "gates") located above the FL are counted as cold precipitation. The rest of the profiles, which are going to be located below the freezing level, are considered as warm precipitation.

Integrated water vapor (IWV, Equation (1), where $g$ is the gravity force, and $q$ is the specific humidity, which is integrated in the vertical column throughout all the vertical $\eta$ model levels) and rain rates have been both obtained from the A-Train's constellation Advanced Microwave Scanning Radiometer for EOS (AMSR-E) and the Advanced Microwave Scanning Radiometer 2 (AMSR-2) products $[27,28]$ in order to compare them with ERA-Interim reanalysis [29] in which the AR detection algorithm is based on.

$$
\begin{aligned}
& I W V=\frac{1}{\mathrm{~g}} \int_{0}^{1} q \frac{\partial p}{\partial \eta} d \eta \\
& I V T=\frac{1}{\mathrm{~g}} \int_{0}^{1} q \vec{u} \frac{\partial p}{\partial \eta} d \eta
\end{aligned}
$$




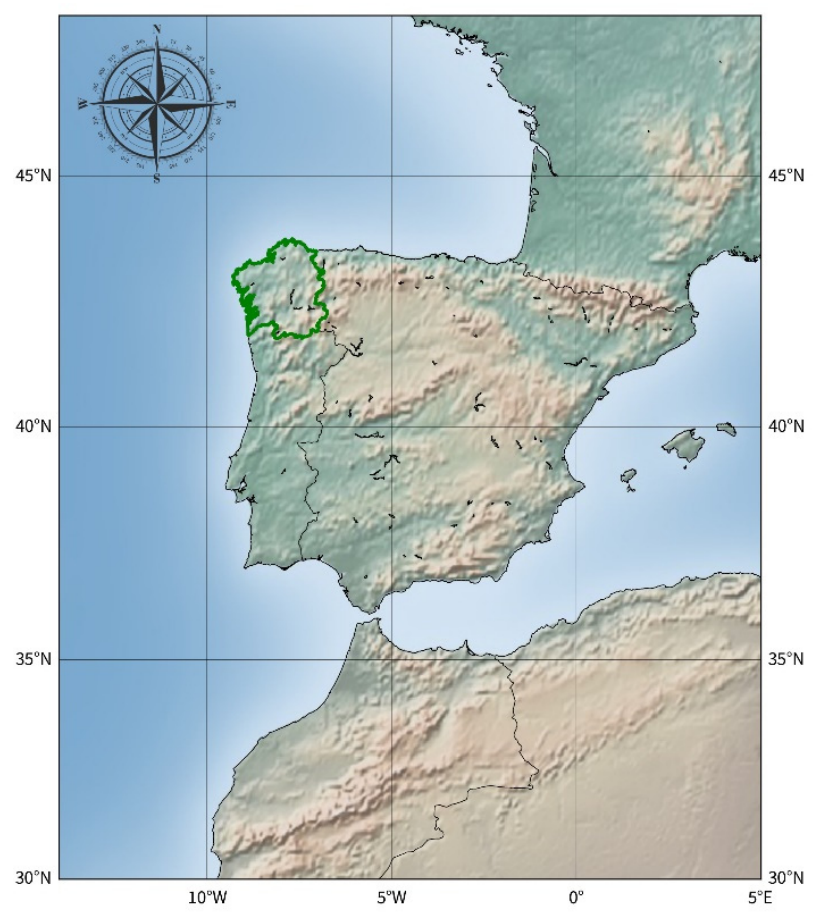

Figure 1. Regional borders of Galicia highlighted in green.

\section{Results}

Figure 2 (day-time) and Figure 3 (night-time) show the 15 AR events analyzed with the methodology described in the previous section. Columns (a) show the ERA-In IWV and Integrated Water Vapor Transport (IVT) fields together with the overpass of the satellite. Columns (b) show the same IWV fields observed using the AMSR sensor, which also retrieves the precipitation rate stated in columns (c). Note that even though every AR event analyzed in this article led to anomalous precipitation, these values of precipitation rate are not the alleged anomalous or extreme accumulated rainfall. These values correspond to the rate of precipitation at the precise moment of the overpass. On the one hand, the coincidence between the overpass and the AR may occur even $24 \mathrm{~h}$ before or after the AR makes landfall. On the other hand, anomalous precipitation events over Galicia usually require large periods of intense precipitation (equal to or longer than $24 \mathrm{~h}$ ) to occur. Values shown in columns c) just provide a snapshot of the precise moment when CloudSat approaches, and not the complete accumulated precipitation that has been labeled as anomalous. Finally, columns d) show the vertical overpass reflectivity in dBZe, together with the specific time of the data acquisition. The freezing level is also displayed in black lines for the last column. All the reflectivities provided by the CloudSat, which is located above the freezing level, are considered cold rain. The reflectivity measured below that level is considered as warm rain. 

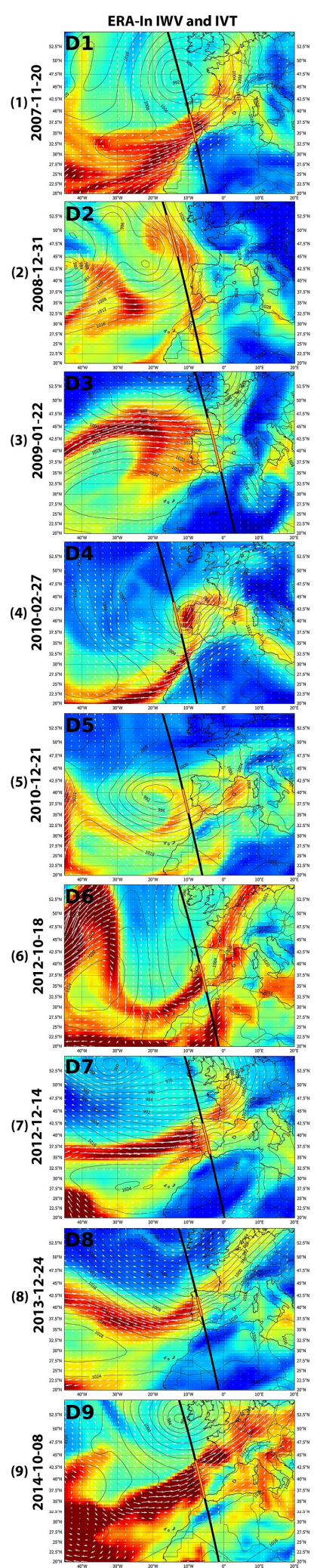

IWV in $\mathbf{~} g \cdot \mathrm{m}^{-2}$

(a)
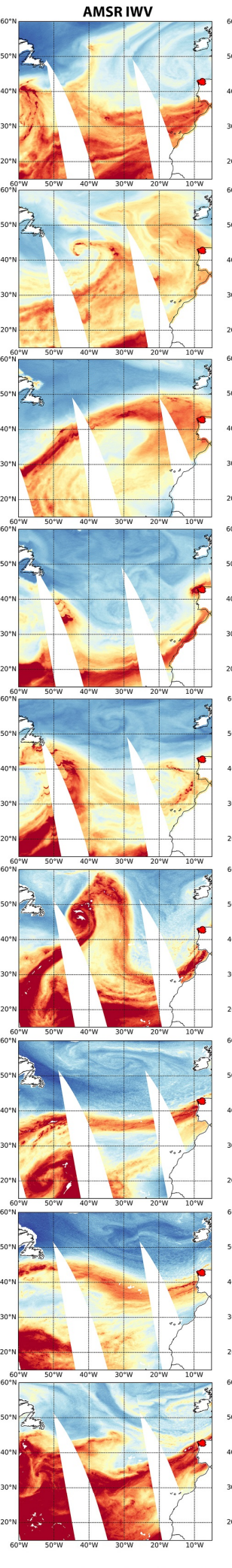

WV in $\mathbf{~ m m}$

(b)
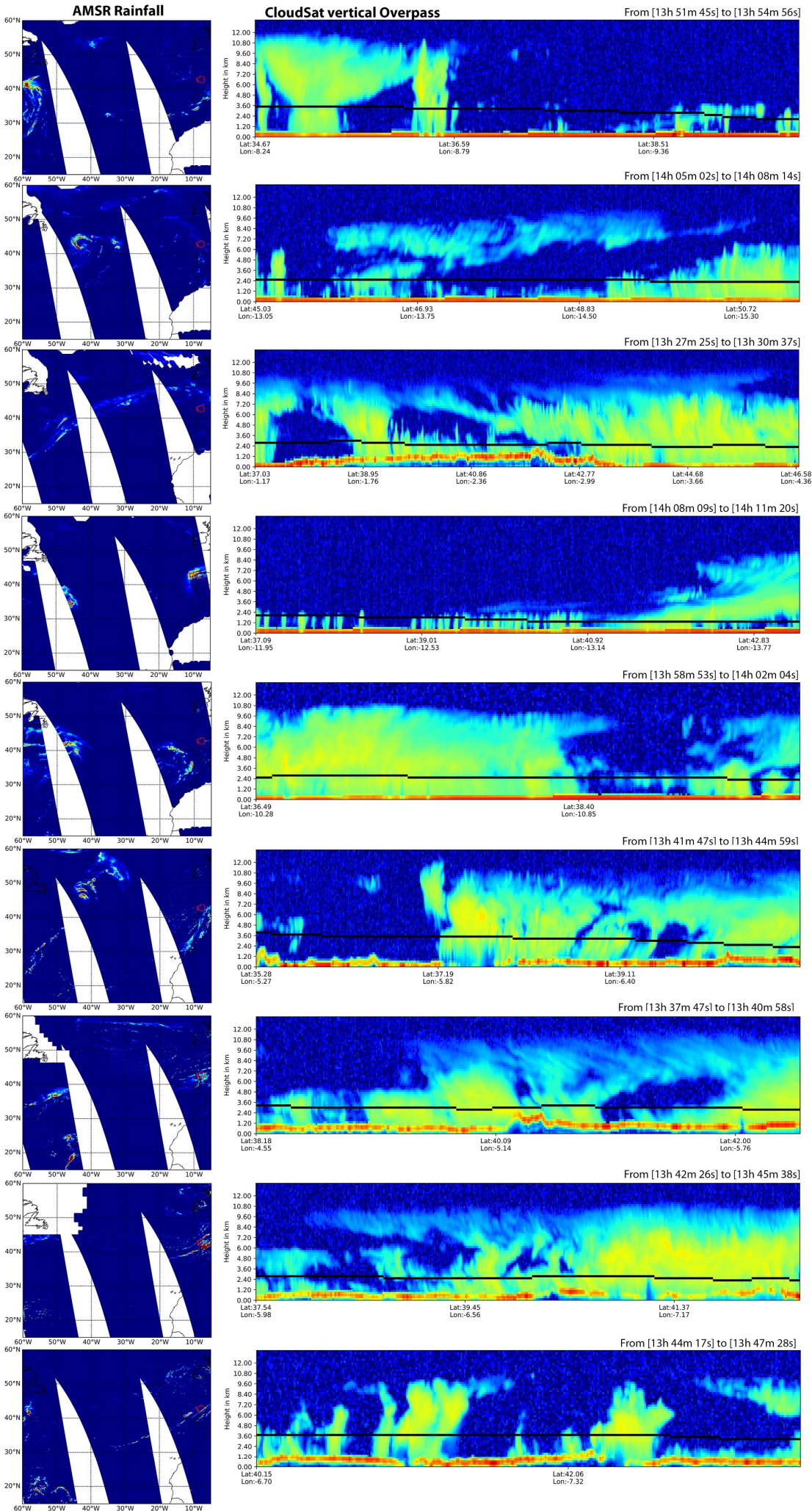

rainfall in $\mathbf{~ m m}$

(c)

Figure 2. Global panel for day-time events. (a) IWV and IVT data from ERA-In at the moment of the AR landfall event in kg.m2. (b) IWV fields from AMSR products in kg.m². (c) Accumulate precipitation in mm/hr. (d) Vertical column reflectivity in $\mathrm{dBZ}$. 

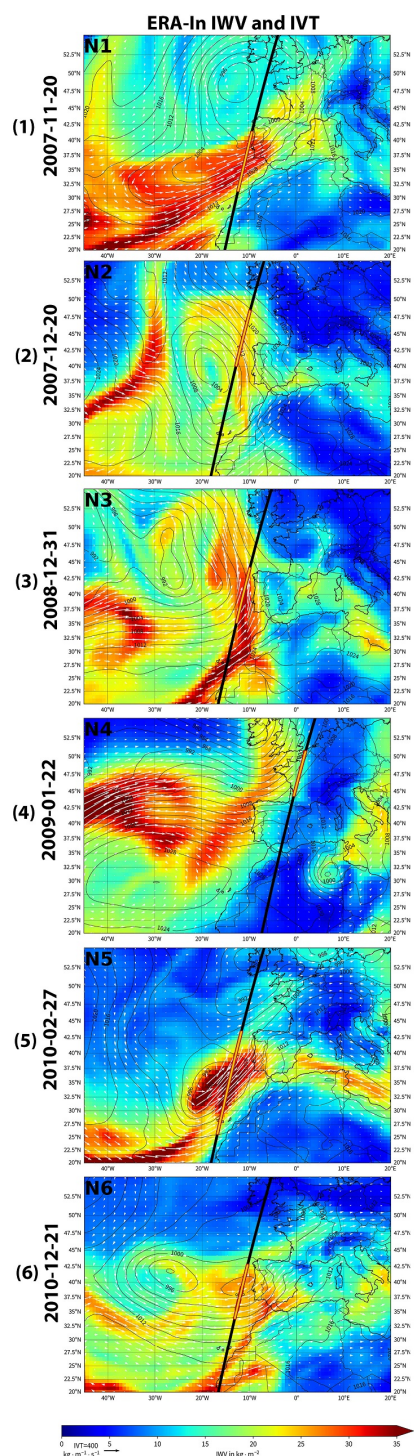

IWV in $\mathrm{kg} \cdot \mathrm{m}^{-2}$

(a)

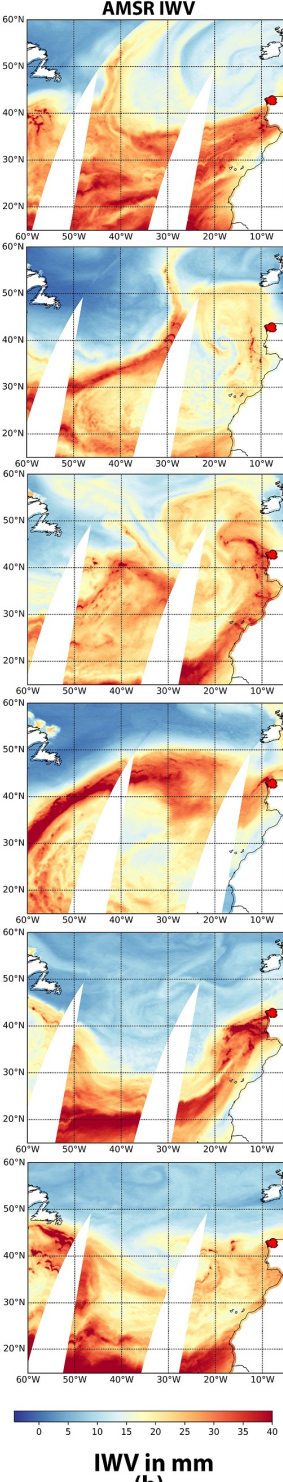

(b)
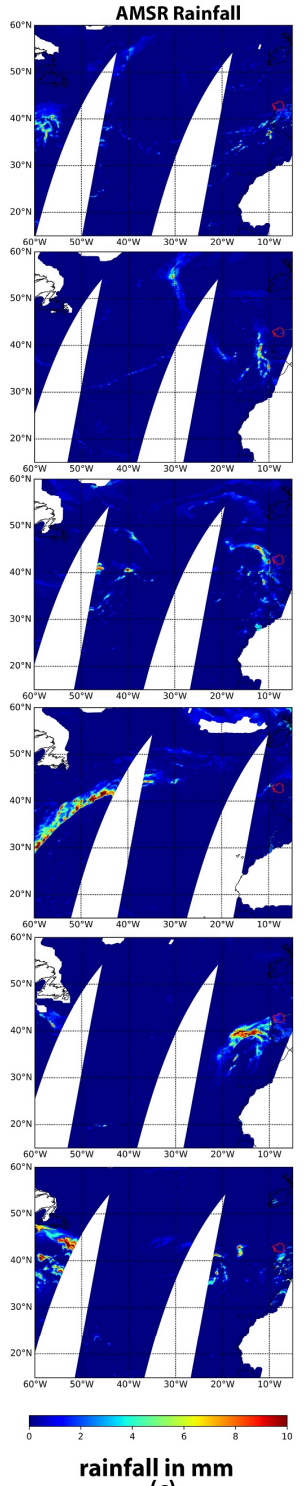

(c)

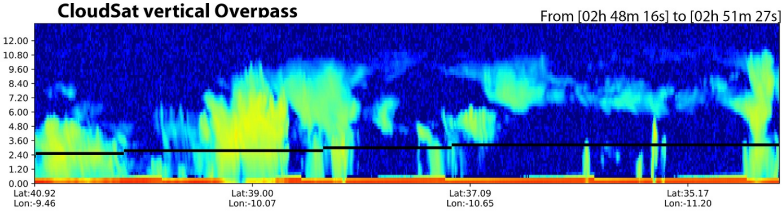

Lat:37.09
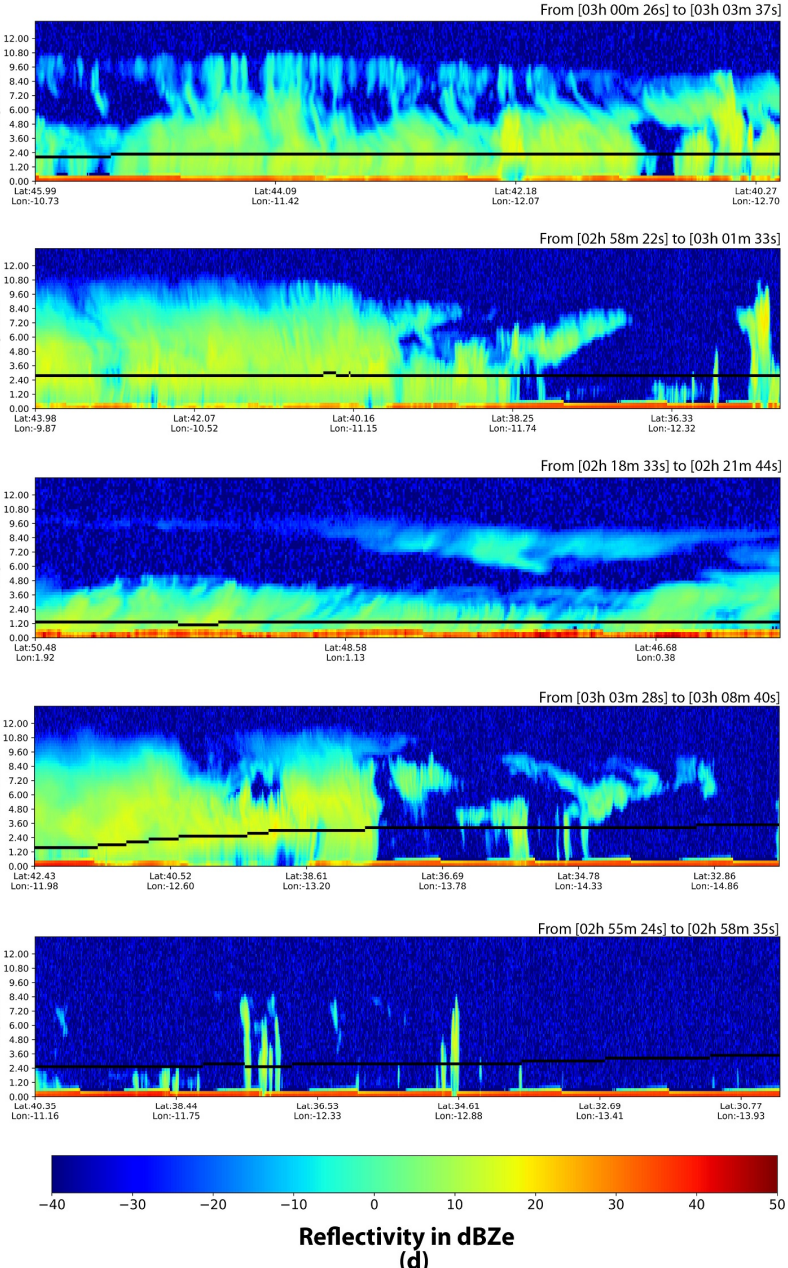

(d)

Figure 3. Same as Figure 2 but for night-time events.

Table 1 summarizes all the results obtained from the analysis of each event - warm and cold fractions were also plotted in Figure 4; these fractions are representative of the reflectivity signal observed above and below the freezing level stated in the columns (d) of Figures 2 and 3. Overall, warm rain accounted for roughly $16.5 \%$ of the precipitation, while the cold type accounted for the remaining $83.5 \%$. The mean precipitation rate was $0.35 \mathrm{~mm} / \mathrm{h}$ and $1.16 \mathrm{~mm} / \mathrm{h}$ for warm and cold precipitation, respectively. Similar values $(0.45 \mathrm{~mm} / \mathrm{h}$ and $1.40 \mathrm{~mm} / \mathrm{h})$ have been calculated by Matrosov [19] for Eastern North Pacific ARs, with a sample of more than 200 AR events. 
Table 1. Measured values of integrated water vapor $(\mathrm{mm})$, rain rate $(\mathrm{mm} / \mathrm{h})$, accumulated precipitation $(\mathrm{mm})$, and fraction of warm and cold precipitation for each atmospheric river (AR) event.

\begin{tabular}{ccccccc}
\hline Event & Date & IWV $(\mathbf{m m})$ & $\mathbf{r r}(\mathbf{m m} / \mathbf{h})$ & Accum.Precip & Warm Ratio & Cold Ratio \\
\hline N1 & 2007-11-20-night & 30 & 0.26 & 74.3 & 0.24 & 0.76 \\
D1 & 2007-11-20-day & 30.4 & 0.2 & 74.3 & 0.21 & 0.79 \\
N2 & 2007-12-20-night & 22.2 & 0.31 & 36.5 & 0.05 & 0.95 \\
N3 & 2008-12-31-night & 31.1 & 0.62 & 19.65 & 0.05 & 0.95 \\
D2 & 2008-12-31-day & 23.4 & 0.08 & 19.65 & 0.39 & 0.61 \\
N4 & 2009-01-22-night & 27.3 & 0.08 & 41.4 & 0.03 & 0.97 \\
D3 & 2009-01-22-day & 28.5 & 0.36 & 41.4 & 0.08 & 0.92 \\
N5 & 2010-02-27-night & 29.4 & 0.96 & 47.61 & 0.01 & 0.99 \\
D4 & 2010-02-27-day & 32.9 & 0.09 & 47.61 & 0.33 & 0.67 \\
N6 & 2010-12-21-night & 23.5 & 0.24 & 40.61 & 0.54 & 0.46 \\
D5 & 2010-12-21-day & 24.4 & 0.86 & 40.61 & 0.06 & 0.94 \\
D6 & 2012-10-18-day & 29.3 & 0.89 & 46.13 & 0.02 & 0.98 \\
D7 & 2012-12-14-day & 31.7 & 0.92 & 86.52 & 0.15 & 0.85 \\
D8 & 2013-12-24-day & 29.5 & 4.23 & 43.45 & 0.09 & 0.91 \\
D9 & 2014-10-08-day & 34.2 & 3.49 & 44.88 & 0.23 & 0.77 \\
\hline
\end{tabular}

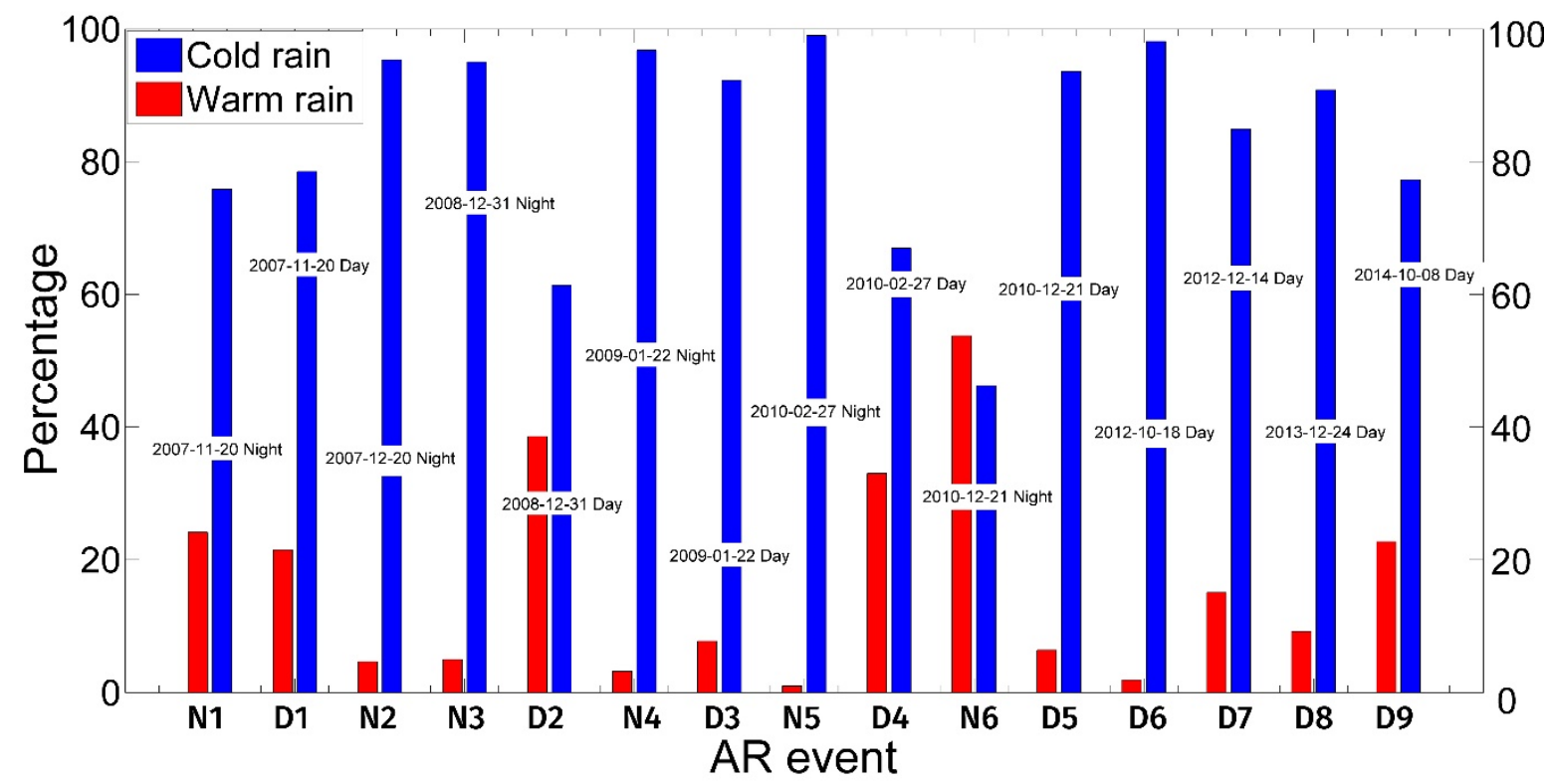

Figure 4. Fraction of cold rain (blue) and warm rain (red) measured for each AR event.

Cold precipitation had a manifest majority presence in our results. However, the variability in the fraction of warm rain was substantial. Thus, it is worth it to discuss the results in terms of the sector of the AR that was analyzed for each case. Before discussing the synoptic conditions associated with each AR event, some concepts should be clarified. Since there is still some disagreement on what can either be considered as an atmospheric river, prefrontal region, or warm conveyor belt; the description and scheme provided in Dettinger et al. [10] will be used here. Under this frame, the AR was considered as the corridor of enhanced advection and convergence of moisture that connected the tropical moisture exports (TME) to the warm conveyor belt (WCB) located at the upper end of the cold front and the occluded front.

On the one hand, only N6 shows warm rain as the dominant type of precipitation. It is important to highlight that, in this case, the overpass does not cut the AR's central axis. Instead, it is coincident with the region of the dynamical structure that can be apparently identified as the WCB. This region of the cyclone is usually characterized by the occlusion 
between the warm and cold conveyor belts, with the former tending to be placed overhead to the latter, enhancing the condensation of the warmer cells by dynamical uplift, and displacing the freezing level to upper levels. This idea fits well with the measurement of enhanced warm rain by CloudSat. Additionally, also D2 and D4 show relatively high ratios of warm precipitation. Once again, the overpass was in both cases covering a complex region of the cyclone, where the interaction between the warm and cold conveyor belts was expected to raise the FL higher levels, leading to more precipitation of the warm branch. On the other hand, there was a set of events where the overpass "cuts" the AR by its central axis, oversea (far away from orographic uplift interactions), and very likely occurring over a well-developed prefrontal region. This is the case of D1 and N1. In these situations, dynamic uplift and adiabatic expansion enhanced by convergence along the prefrontal region will be the main triggering mechanism for condensation. Additionally, the low-level jet will be well developed and enhanced by thermal wind temperature gradient. D6, D9, and D8 also show a clear cut of the central axis of their respective ARs, but the orographic interaction cannot be ruled out for these cases. All these events show cold rain ratios close to-or higher than -0.8 .

\section{Discussion}

Lower precipitation rates are usually associated with coalescence processes in shallow precipitating clouds. Higher precipitation rates are usually associated with processes arisen from synoptic forcing, in deeper cloud layers, and even convective mechanisms (e.g., [30,31]).

In the absence of a more comprehensive and conclusive statistic, it seemed that warm precipitation plays a secondary role along the axis of a well-developed AR, where the bulk of the moisture remains in the lower levels. In this region of the system, it was the cold precipitation that plays the main role. It seems to be precisely within the interaction between the warm conveyor and the cold conveyor belt, at the upper end of the AR structure, where the FL may eventually raise upper vertical levels, and subsequently, where warm precipitation can play a more important role.

Even though precipitation rates associated with each type of precipitation are similar to those already reported in the literature, the relative presence between warm precipitations observed in this analysis is lower than that reported by Matrosov [19] for the US Pacific Coast. In this experiment, the authors took the maximum possible number of events with a clear interaction between the CloudSat overpass and an AR that led to anomalous precipitation over Galicia. Still, we recognized that this experiment was fairly limited in the size of the sample. However, this research was not intended to provide final conclusions or climatological rates of warm rainfall versus the cold counterpart. This paper aimed to provide a first approach to the issue that will be further extended in the future by extending the area of study, and expanding the analysis to the summer months. This database can also be extended or contrasted to that obtained using the $\mathrm{Ku} / \mathrm{Ka}$-band dual-frequency precipitation radar (DPR, [32]). This sensor is aboard the global precipitation measurement (GPM) satellite and may be used in the future to update and improve the results presented here.

\section{Conclusions}

This analysis provided an account of the ratio of warm precipitation versus cold precipitation analyzed from satellite data for 15 AR events landfalling the Spanish region of Galicia in the winter season. Even showing a substantial variability between events, the warm precipitation was shown to be secondary, accounting for less than $20 \%$ of the measured rainfall.

Only 3 out of the 15 events show warm ratios higher than $30 \%$. These three events had the peculiarity that the overpass measurements were not carried out over the central axis of the AR. On the contrary, the satellite's overpass analyzed a region closer to the 
dynamic core of the cyclone, which is usually characterized by the interaction between the warm and the cold conveyor belts. In this region, the warm conveyor belt tended to overlap the cold conveyor belt, ascending to higher levels and consequently raising the freezing level. In the remaining events, both in which the overpass clearly cut the AR, and also in those that occur in different regions of the dynamic system (or overland, where orographic interactions cannot be discarded), cold rain ratios were close or higher to 0.8 .

Author Contributions: R.N., L.G., A.M.R., and M.F. had the initial idea and supervised the work. I.A., E.G., and J.E.-B. carried out the analysis. All of the authors collaborated in the writing of the manuscript. All authors have read and agreed to the published version of the manuscript.

Funding: J.E.-B. was financially supported by the EDB481B 2018/069 grant from the Xunta de Galicia, Spain and the Fulbright Commission, US. This work is part of the LAGRIMA project funded by Ministerio de Ciencia, Innovación y Universidades, Spain. This work was also partially supported by Xunta de Galicia, Spain under Project ED431C 2017/64 GRC “Programa de Consolidación e Estructuración de Unidades de Investigación Competitivas (Grupos de Referencia Competitiva)". This work is supported by the LAGRIMA project (grant no. RTI2018-095772-B-I00) funded by the Ministerio de Ciencia, Innovación y Universidades, Spain. Partial support was also obtained from the Xunta de Galicia, Spain, under the project "Programa de Consolidación e Estructuración de Unidades de Investigación Competitivas (Grupos de Referencia Competitiva)" (no. ED431C 2017/64GRC). Both programs are co-funded by FEDER (European Regional Development Fund (ERDF)) by the European Union.

Acknowledgments: The authors would like to thank the Centro de Supercomputación de Galicia (CESGA) for providing the necessary computational resources for the analysis. E.G. wants to thank all the EPhyslab faculty and staff for the good treatment received in Ourense (Spain) during her Ph.D. student visiting scholar stay. E.G. also wants to thank Y.S. Matrosov for the fruitful discussions and help provided.

Conflicts of Interest: The authors declare no conflict of interest.

\section{References}

1. Egimeno, L.; Enieto, R.; Vãjzquez, M.; Lavers, D.A. Atmospheric rivers: A mini-review. Front. Earth Sci. 2014, 2, doi:10.3389/feart.2014.00002.

2. Ralph, F.M.; Neiman, P.J.; Wick, G.A.; Gutman, S.I.; Dettinger, M.D.; Cayan, D.R.; White, A.B. Flooding on California's Russian River: Role of atmospheric rivers. Geophys. Res. Lett. 2006, 33, doi:10.1029/2006gl026689.

3. Leung, L.R.; Qian, Y. Atmospheric rivers induced heavy precipitation and flooding in the western U.S. simulated by the WRF regional climate model. Geophys. Res. Lett. 2009, 36, doi:10.1029/2008g1036445.

4. Dettinger, M.D. Atmospheric Rivers as Drought Busters on the U.S. West Coast. J. Hydrometeorol. 2013, 14, 1721-1732, doi:10.1175/jhm-d-13-02.1.

5. Lavers, D.A.; Villarini, G. The nexus between atmospheric rivers and extreme precipitation across Europe. Geophys. Res. Lett. 2013, 40, 3259-3264, doi:10.1002/grl.50636.

6. Neff, W. Atmospheric rivers melt Greenland. Nat. Clim. Chang. 2018, 8, 857-858, doi:10.1038/s41558-018-0297-4.

7. Kamae, Y.; Mei, W.; Xie, S.-P.; Naoi, M.; Ueda, H. Atmospheric Rivers over the Northwestern Pacific: Climatology and Interannual Variability. J. Clim. 2017, 30, 5605-5619, doi:10.1175/jcli-d-16-0875.1.

8. Bozkurt, D.; Rondanelli, R.; Marín, J.C.; Garreaud, R. Foehn Event Triggered by an Atmospheric River Underlies Record-Setting Temperature Along Continental Antarctica. J. Geophys. Res. Atmos. 2018, 123, 3871-3892, doi:10.1002/2017jd027796.

9. Blamey, R.C.; Ramos, A.M.; Trigo, R.M.; Tomé, R.; Reason, C.J.C. The Influence of Atmospheric Rivers over the South Atlantic on Winter Rainfall in South Africa. J. Hydrometeorol. 2018, 19, 127-142, doi:10.1175/jhm-d-17-0111.1.

10. Dettinger, M.; Ralph, F.M.; Lavers, D. Setting the Stage for a Global Science of Atmospheric Rivers. Eos 2015, 96, doi:10.1029/2015eo038675.

11. Eiras-Barca, J.; Brands, S.; Miguez-Macho, G. Seasonal variations in North Atlantic atmospheric river activity and associations with anomalous precipitation over the Iberian Atlantic Margin. J. Geophys. Res. Atmos. 2016, 121, 931-948, doi:10.1002/2015jd023379.

12. Lavers, D.A.; Richardson, D.S.; Ramos, A.M.; Zsoter, E.; Pappenberger, F.; Trigo, R.M. Earlier awareness of extreme winter precipitation across the western Iberian Peninsula. Meteorol. Appl. 2018, 25, 622-628, doi:10.1002/met.1727.

13. Ramos, A.M.; Martins, M.J.; Tomé, R.; Trigo, R.M. Extreme Precipitation Events in Summer in the Iberian Peninsula and Its Relationship With Atmospheric Rivers. Front. Earth Sci. 2018, 6, doi:10.3389/feart.2018.00110.

14. Ramos, A.M.; Trigo, R.M.; Liberato, M.L.; Tomé, R. Daily precipitation extreme events in the Iberian Peninsula and its association with atmospheric rivers. J. Hydrometeorol. 2015, 16, 579-597. 
15. Behrangi, A.; Guan, B.; Neiman, P.J.; Schreier, M.; Lambrigtsen, B. On the Quantification of Atmospheric Rivers Precipitation from Space: Composite Assessments and Case Studies over the Eastern North Pacific Ocean and the Western United States. J. Hydrometeorol. 2015, 17, 369-382, doi:10.1175/jhm-d-15-0061.1.

16. Neiman, P.J.; Ralph, F.M.; Wick, G.A.; Kuo, Y.-H.; Wee, T.-K.; Ma, Z.; Taylor, G.H.; Dettinger, M.D. Diagnosis of an Intense Atmospheric River Impacting the Pacific Northwest: Storm Summary and Offshore Vertical Structure Observed with COSMIC Satellite Retrievals. Mon. Weather. Rev. 2008, 136, 4398-4420, doi:10.1175/2008mwr2550.1.

17. Ralph, F.M.; Neiman, P.J.; Wick, G.A. Satellite and caljet aircraft observations of atmospheric rivers over the eastern north pacific ocean during the winter of 1997/98. Mon. Weather. Rev. 2004, 132, 1721-1745.

18. Suzuki, K.; Stephens, G.L.; Heever, S.C.V.D.; Nakajima, T.Y. Diagnosis of the Warm Rain Process in Cloud-Resolving Models Using Joint CloudSat and MODIS Observations. J. Atmospheric Sci. 2011, 68, 2655-2670, doi:10.1175/jas-d-10-05026.1.

19. Matrosov, S.Y. Characteristics of Landfalling Atmospheric Rivers Inferred from Satellite Observations over the Eastern North Pacific Ocean. Mon. Weather. Rev. 2013, 141, 3757-3768, doi:10.1175/mwr-d-12-00324.1.

20. Guan, B.; Waliser, D.E. Detection of atmospheric rivers: Evaluation and application of an algorithm for global studies. J. Geophys. Res. Atmos. 2015, 120, 12514-12535, doi:10.1002/2015jd024257.

21. Stephens, G.L.; Vane, D.G.; Boain, R.J.; Mace, G.G.; Sassen, K.; Wang, Z.; Illingworth, A.J.; O'connor, E.J.; Rossow, W.B.; Durden, S.L.; et al. The cloudsat mission and the a-train: A new dimension of space-based observations of clouds and precipitation. Bull. Am. Meteorol. Soc. 2002, 83, 1771-1790.

22. Stephens, G.L.; Vane, D.G.; Tanelli, S.; Im, E.; Durden, S.; Rokey, M.; Reinke, D.; Partain, P.; Mace, G.G.; Austin, R.; et al. CloudSat mission: Performance and early science after the first year of operation. J. Geophys. Res. Space Phys. 2008, 113, doi:10.1029/2008jd009982.

23. Lorenzo, M.N.; Taboada, J.J.; Gimeno, L. Links between circulation weather types and teleconnection patterns and their influence on precipitation patterns in Galicia (NW Spain). Int. J. Clim. 2007, 28, 1493-1505, doi:10.1002/joc.1646.

24. Matrosov, S.Y. Observations of Wintertime U.S. West Coast Precipitating Systems with W-Band Satellite Radar and Other Spaceborne Instruments. J. Hydrometeorol. 2012, 13, 223-238, doi:10.1175/jhm-d-10-05025.1.

25. Field, P.R.; Heymsfield, A.J. Importance of snow to global precipitation. Geophys. Res. Lett. 2015, 42, 9512-9520, doi:10.1002/2015g1065497.

26. Lebsock, M.D.; L'Ecuyer, T.S. The retrieval of warm rain from CloudSat. J. Geophys. Res. Space Phys. 2011, 116, 20209, doi:10.1029/2011jd016076.

27. Kawanishi, T.; Sezai, T.; Ito, Y.; Imaoka, K.; Takeshima, T.; Ishido, Y.; Shibata, A.; Miura, M.; Inahata, H.; Spencer, R. The advanced microwave scanning radiometer for the earth observing system (AMSR-E), NASDA's contribution to the EOS for global energy and water cycle studies. IEEE Trans. Geosci. Remote. Sens. 2003, 41, 184-194, doi:10.1109/tgrs.2002.808331.

28. Imaoka, K.; Kachi, M.; Kasahara, M.; Ito, N.; Nakagawa, K.; Oki, T. Instrument performance and calibration of amsr-e and amsr2. Int. Arch. Photogramm. Remote Sens. Spat. Information Sci. 2010, 38, 13-18.

29. Dee, D.P.; Uppala, S., Simmons, A.; Berrisford, P.; Poli, P.; Kobayashi, S.; Andrae, U.; Balmaseda, M.; Balsamo, G.; Bauer, P.; et al. The era-interim reanalysis: Configuration and performance of the data assimilation system. Q. J. R. Meteorol. Soc. 2011, 137, 553-597.

30. Cannon, F.; Ralph, F.M.; Wilson, A.M.; Lettenmaier, D.P. GPM Satellite Radar Measurements of Precipitation and Freezing Level in Atmospheric Rivers: Comparison with Ground-Based Radars and Reanalyses. J. Geophys. Res. Atmos. 2017, 122, 12-747, doi:10.1002/2017jd027355.

31. Martner, B.E.; Yuter, S.E.; White, A.B.; Matrosov, S.Y.; Kingsmill, D.E.; Ralph, F.M. Raindrop Size Distributions and Rain Characteristics in California Coastal Rainfall for Periods with and without a Radar Bright Band. J. Hydrometeorol. 2008, 9, 408-425, doi:10.1175/2007jhm924.1.

32. Iguchi, T.; Seto, S.; Meneghini, R.; Yoshida, N.; Awaka, J.; Kubota, T. Gpm/Dpr Level-2 Algorithm Theoretical Basis Document; NASA Goddard Space Flight Center: Greenbelt, MD, USA, 2010. 